\title{
UM PROJETO DE OLIMPÍADA DE MATEMÁTICA NO MUNICÍPIO DE SANTANA DO ARAGUAIA PARÁ
}

\section{ARTIGO ORIGINAL}

SILVEIRA, Helves Belmiro da ${ }^{1}$, OLIVEIRA, Cláudio José de ${ }^{2}$

SILVEIRA, Helves Belmiro da. OLIVEIRA, Cláudio José de. Um projeto de olimpíada de matemática no município de Santana do Araguaia Pará. Revista Científica Multidisciplinar Núcleo do Conhecimento. Ano. 07, Ed. 01, Vol. 03, pp. 68-80. Janeiro de 2022. ISSN: 2448-0959, Link de acesso: https://www.nucleodoconhecimento.com.br/matematica/olimpiada-dematematica

\section{RESUMO}

O presente trabalho é resultado de uma experiência com o projeto de extensão intitulado de OSMEM - Olimpíadas Santanense de Matemática das Escolas Municipais que levou ao conhecimento dos alunos questões relacionadas a olimpíadas e suas diferentes maneiras de soluciona-las, vinculado a UNIFESSPA Universidade Federal do Sul e Sudeste do Pará e ao curso de licenciatura plena em matemática. Teve como questionamento norteador: por que estudar matemática em um contexto olímpico? Teve-se como objetivo alavancar o desenvolvimento da disciplina de matemática no município e despertar nos estudantes do $6^{\circ}$ ao $9^{\circ}$ ano do ensino fundamental o gosto de aprender matemática, objetiva-se, ainda, estimular a participação em eventos olímpicos nacionais relacionados a matemática. A metodologia utilizada no desenvolver do projeto contou com aulas expositivas ligadas as questões de olimpíadas de matemática realizadas em todo território brasileiro. Fazse necessário uma análise da contribuição dos projetos de extensão realizados pelas

\footnotetext{
${ }^{1}$ Mestre em Matemática. ORCID: https://orcid.org/0000-0002-7724-3911

2 Doutor em Educação. ORCID: https://orcid.org/0000-0002-9403-0897

RC: 104950

Disponível em: https://www.nucleodoconhecimento.com.br/matematica/olimpiada-dematematica
} 
universidades junto a toda comunidade e seus benefícios na área acadêmica e social de cidades onde são implementados. Os resultados atingidos pelo projeto foram a compreensão da matemática abstrata em nível fundamental, a parceria com professores da rede municipal de ensino, a melhora na disciplina de matemática pelos alunos participantes do projeto além de promover o ensino docente por partes dos acadêmicos envolvidos nas etapas de execução desse projeto de extensão.

Palavras-chave: Ensino, Olimpíada de Matemática, Matemática, Projetos de Extensão.

\section{INTRODUÇÃO}

O presente artigo é fruto de um projeto de extensão universitária denominado de OSMEM - Olimpíadas Santanense de Matemática da Escolas Municipais, no município de Santana do Araguaia, região Sul do Estado do Pará, tal projeto foi criado pelo Docente Professor Mestre Helves Belmiro da Silveira com a colaboração de alguns acadêmicos e professores do curso de licenciatura plena em matemática, a fim de melhorar o rendimento na disciplina de matemática nesse município, e posteriormente tentar fazer com que os discentes de $6^{\circ}$ a $9^{\circ}$ ano do ensino fundamental melhorassem seus resultados na olimpíada brasileira de matemática das escola públicas.

Um outro destaque deste trabalho é mostrar o quanto os projetos de extensão universitários são bem-vindos a comunidade em geral onde são executados o que é defendido por Gadotti (2017), favorecendo o desenvolvimento intelectual de todos os envolvidos, além de apontar soluções e direcionamentos nas futuras ações que as universidades públicas podem desenvolver em benefício dos grupos sociais de menor renda e cultura, trançando novos caminhos e futuras perspectivas no âmbito educacional. 
Neste contexto, teve como questionamento norteador: por que estudar matemática em um contexto olímpico? Teve-se como objetivo alavancar o desenvolvimento da disciplina de matemática no município e despertar nos estudantes do $6^{\circ}$ ao $9^{\circ}$ ano do ensino fundamental o gosto de aprender matemática, objetiva-se, ainda, estimular a participação em eventos olímpicos nacionais relacionados a matemática.

Vale ressaltar que as políticas públicas educacionais têm papel de suma importância nos projetos de extensão desenvolvidos nas comunidades, e no caso deste trabalho a Secretaria de Educação do município de Santana do Araguaia colaborou na divulgação e organização uma olimpíada de matemática, e a mesma só não se executou de forma presencial por agravamento na pandemia do COVID-19.

\section{PROJETOS DE EXTENSÃO UNIVERSITÁRIA}

Em seus escritos Santos; Rocha e Passaglio (2016) afirmam que a extensão universitária é um complemento de interação que por teoria deve haver no contexto acadêmico e que envolve a comunidade e a universidade, seria comparado a uma espécie de via de mão dupla entre as universidades e as diferentes camadas da sociedade. Funciona como uma ponte onde é transitado o conhecimento levado pelas unidades acadêmicas juntamente com toda a assistência superior pretendida as diversas camadas da sociedade, e em contrapartida a sociedade alimenta esse fluxo com as necessidades reais a serem trabalhadas nos diversos setores de atuação das universidades, formando assim profissionais com maior capacidade intelectual, uma formação digna e de qualidade.

É importante ressaltar os escritos de Rodrigues et al. (2013, p. 142)

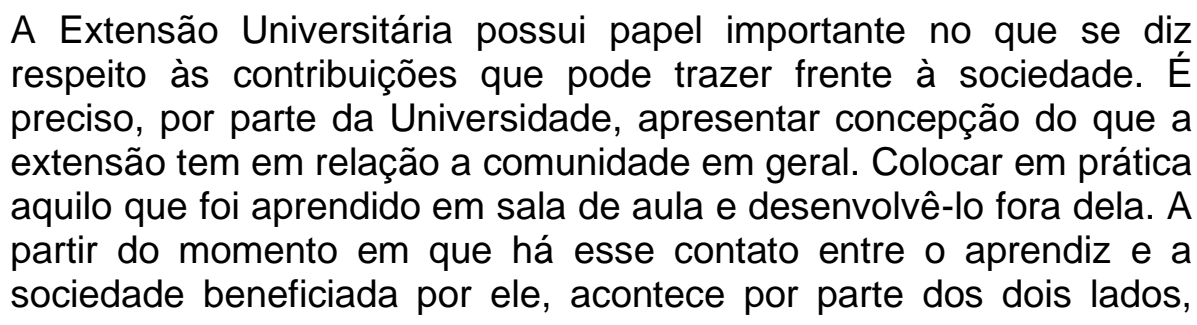

RC: 104950

Disponível em: https://www.nucleodoconhecimento.com.br/matematica/olimpiada-dematematica 
benefícios. Aquele que está na condição do aprender acaba aprendendo muito mais quando há esse contato, pois torna-se muito mais gratificante praticar a teoria recebida dentro da sala de aula. Esse é o conceito básico de extensão.

É certo que nessa troca de experiências, a academia desenvolve um aprendizado sistemático dos saberes das comunidades envolvidas nesses projetos de extensão. Sabe-se que as universidades como vimos hoje e desde sua criação no Brasil foram instrumentos criados para atender necessidades da nação e gradativamente vem sendo distribuídas em todo o território nacional. Sua vertente é sempre estar ligada ao desenvolvimento cultural, social, intelectual e político das comunidades onde são implementadas.

Para Castro (2004) em alguns aspectos é considerado um privilégio a conquista universitária juntamente com sua produção de conhecimento para os cidadãos que por ela são atingidos. Analisando o plano nacional de extensão, planejado pelos próreitores de extensão das universidades públicas de todo o Brasil e em parceria com a secretaria do ensino superior do MEC, consideram a extensão universitária como um processo educativo envolvendo a cultura e a ciência, articulando a pesquisa e o ensino de forma indissociável e viabilizando a relação transformadora entre as universidades e a sociedade.

Nessa vertente compreender a abstrata relação entre as universidades e a sociedade, necessita-se resgatar o aspecto de extensão universitária enquanto processo das comunidades que permitiriam a participação de grupos excluídos historicamente. Com a troca de conhecimentos as universidades e a sociedade desenvolvem projetos para a melhoria social das comunidades onde eles são implementados.

Segundo Nunes e Silva (2011, p. 120)

O fortalecimento da relação universidade/sociedade prioriza a superação das condições de desigualdades e exclusão existentes. Através de projetos sociais, a universidade socializa seu conhecimento e disponibiliza seus serviços, exercendo sua

RC: 104950

Disponível em: https://www.nucleodoconhecimento.com.br/matematica/olimpiada-dematematica 
responsabilidade social, ou mesmo sua missão: o compromisso com a melhoria da qualidade de vida dos cidadãos.

O que deixa claro que a troca de parcerias entre o espaço universitário atrelado a sociedade beneficia ambas as partes envolvidas, dando acesso as minorias e contribuindo de forma significativa com o desenvolvimento da ciência nas mais diversas áreas universitárias por todo o país.

\section{OLIMPÍADAS DE MATEMÁTICA E SEU SURGIMENTO}

Um fato curioso da história da matemática eram os desafios proporcionados por matemáticos conhecidos e os que estavam em ascensão. Esses desafios eram organizados e disputados em praças públicas, eles eram compostos de até 30 questões de cada oponente e se declarava o vencedor aquele que conseguisse solucionar o maior número de itens de seu adversário.

Segundo Maciel e Basso (2009) só em 1894 foram realizadas as primeiras competições relacionadas a conhecimento matemático, isso ocorreu na Hungria e contou com a participação dos alunos concluintes do então $2^{\circ}$ grau. Vale ressaltar que a competição foi a nível nacional e que ela tinha como objetivo homenagear o professor de matemática Jósef Kürschák, membro da academia de ciências daquele país. Curiosamente o ponta pé inicial para a realização das olimpíadas modernas também foi dado pelo comitê olímpico internacional (COI) no ano de 1894, e sua primeira competição foi em Atenas em 1896.

Como dito por Maciel e Basso (2009) em 1934 foi realizada a primeira olimpíada de matemática da era moderna, ocorrida na cidade de Leningrado, hoje conhecida como São Petersburgo na Rússia, esse modelo foi mais tarde copiado pelos países do leste da Europa, União Soviética o que por consequência originou a Olimpíada Internacional de Matemática (IMO), que teve sua primeira edição realizada em Bucareste na Romênia no ano de 1959, e com o passar dos anos atingiu centenas de

RC: 104950

Disponível em: https://www.nucleodoconhecimento.com.br/matematica/olimpiada-dematematica 
países dos cinco continentes. O Brasil foi o primeiro dos países da américa do sul a participar dessa competição no ano de 1979.

Nesse mesmo ano a Sociedade Brasileira de Matemática (SBM) e o Instituto de Matemática Pura e Aplicada (IMPA) criaram a primeira Olimpíada Brasileira de Matemática $(\mathrm{OBM})$, onde os participantes eram alunos da $5^{\underline{a}}$ série até $03^{\circ}$ ano do segundo grau, além disso, nessa mesma olimpíada permitiu-se a participação de acadêmicos, e o acesso a competições internacionais de matemática.

Por outro lado, o modelo que é conhecido hoje como Olimpíadas Brasileira de Matemática das Escolas Públicas (OBMEP), foi criada em 2005 e sua coordenação é de responsabilidade do Ministério da Educação e da Ciência e Tecnologia em parceria com a SBM, cujo objetivo é descobrir novos talentos nesse segmento. Essa olimpíada é aplicada para alunos do $6^{\circ}$ ano do ensino fundamental ao $3^{\circ}$ ano do ensino médio e se subdivide em três níveis de conhecimento: o nível 1 é composto por estudantes do $6^{\circ}$ e $7^{\circ}$ anos; o nível 2 é composto por alunos do $8^{\circ}$ e $9^{\circ}$ anos; e por fim o nível 3 é formado pelos alunos do ensino médio contemplando os três anos desse nível. Vale ressaltar que essa olimpíada é dividida em duas etapas, a primeira etapa engloba todos os alunos matriculados e a prova é composta de questões objetivas e apenas $5 \%$ dos alunos são classificados para a segunda fase, onde as provas são de cunho discursivo.

Em seus escritos Maciel e Basso (2009) ressaltam que no país existem várias competições matemáticas que se assemelham e preparam os alunos para essas olimpíadas, esses eventos são a níveis estaduais e municipais e buscam sempre a melhoria e o desenvolvimento matemático dessas regiões. Dentre essas competições destacam-se a Olimpíada Cearense de Matemática (COM), Olimpíada de Matemática do Estado do Rio de Janeiro (OMERJ), a Olimpíada Paulista de Matemática (OPM), e a Olimpíada Mineira de Matemática (OMM). 
Nesse sentido e com essa inquietação surgiu a ideia de criar o projeto de extensão intitulado de Olimpíada Santanense de Matemática das Escolas Municipais (OSMEM), o principal objetivo foi melhorar o nível matemático dos alunos do $6^{\circ}$ ao $9^{\circ}$ do ensino fundamental do município de Santana do Araguaia, município situado do Sul do estado do Pará, e que possui em seu território um campus da Universidade Federal do Sul e Sudeste do Pará (UNIFESSPA) onde o projeto foi pensado e executado.

\section{A CRIAÇÃO DO PROJETO OSMEM}

Ao se observar o baixo desempenho apresentado por uma boa parcela dos alunos em matemática no ensino fundamental e médio, fica evidenciado o enorme desafio ligado ao processo de ensino e aprendizagem durante essa fase escolar relacionada a disciplina de matemática nas unidades escolares públicas do nosso país. Esta realidade é suficiente para alimentar a visão de que a matemática é uma disciplina abstrata, formal, de difícil compreensão e, portanto, de distante alcance.

Embora esteja rodeado de produtos e novidades tecnológicas elaboradas graças aos conhecimentos matemáticos e suas relações com as diversas áreas do conhecimento humano, ainda não é o bastante para convencer ou motivar o aluno a se dedicar ao aprendizado desta disciplina. O que se vê é a procura insuficiente da sociedade a esse tipo de conhecimento específico e técnico, ao se ensinar a disciplina de matemática o docente tem que adotar metodologias dinâmicas, inovadores e interessantes para desmistificar o mito de um conteúdo complicado, e quem sabe com essas novas atitudes possa se acabar com a visão de que seu aprendizado é algo inalcançável.

Convencer o estudante do fato de que aprender matemática pode ser algo prazeroso e acessível torna-se uma tarefa difícil por parte dos professores da educação básica, visto que a carga horária de trabalho deles é enorme, e em alguns casos chegam aos três turnos. Isso implica em um trabalho aguerrido, que necessita além de bastante criatividade e conhecimento, requer uma infraestrutura física e recursos financeiros

RC: 104950

Disponível em: https://www.nucleodoconhecimento.com.br/matematica/olimpiada-dematematica 
que permitam desenvolver o raciocínio, a percepção e, sobretudo, a aplicabilidade na prática diária do conjunto de temas que estão sendo transmitidos.

Nesse cenário, o educador tem que assumir o desafio proposto, e não se pode esquecer de que esse professor deve estar preparado para tal desafio como defendido por Gomes (2019). É coerentemente verídico que uma grande parcela dos docentes não possui bons ambientes para a execução do seu trabalho. Ainda existe um problema que pode ser considerado nesse processo, a falta de formação em sua área específica. Esses são alguns fatores que infelizmente tem influência e contribuem de forma negativa para a falta de sucesso no ensino de matemática.

Diante dessa realidade é necessária e esperada uma intervenção da Universidade afim de contribuir positivamente na qualidade do ensino da matemática na educação pública de Santana do Araguaia. Não descuidados a para tal realidade, e tendo em vista a projeção de bons resultados da Olimpíada Brasileira de Matemática das Escolas Públicas (OBMEP), esse projeto exposto nesse escrito é intitulado Olimpíada Santanense de Matemática das Escolas Municipais (OSMEM), representa o esforço do governo municipal, servidores e alunos da UNIFESSPA, e em companhia com os professores da rede básica do município de Santana do Araguaia, de provocar nos estudantes da educação básica maior interesse e dedicação pelo aprendizado da disciplina matemática.

A OSMEM possui o grande desafio de integrar professores e alunos da UNIFESSPA e da rede pública de ensino de Santana do Araguaia para que juntos possam elaborarem estratégias, e da mesma maneira recursos didáticos para o ensino que gerem transformações, não apenas na expectativa do aprendizado de matemática, mais também na percepção da seriedade da educação como instrumento de desenvolvimento e de transformação social.

RC: 104950

Disponível em: https://www.nucleodoconhecimento.com.br/matematica/olimpiada-dematematica 


\section{O PORQUÊ DA CRIAÇÃO DA OSMEM}

A criação da Universidade Federal do Sul e Sudeste do Pará (UNIFESSPA), segundo o seu Plano de Desenvolvimento Institucional (PDI), é reflexo da necessidade de melhorar a qualidade da educação na região. Assim, a OSMEM representa um esforço de professores e alunos que são conhecedores e que compartilham os desafios do ensino da matemática de, em consonância com o PDI da UNIFESSPA, concretizar ações de intervenção na atual condição da educação básica, principalmente no que se refere ao ensino da matemática na região sul e sudeste do país.

A OSMEM implicará em inclusão social dos contemplados pelas ações educativas deste projeto, uma vez que os mesmos, além de serem preparados para as provas da OSMEM, também serão incentivados a participar da OBMEP e do ENEM e serão estimulados a investir na educação como condição para ascensão social.

A proposta da OSMEM, desenvolvida baseada nas ideias da OBMEP, representa um projeto de grande alcance e complexidade, uma vez que exigirá uma integração entre docentes e graduandos do curso de Licenciatura em Matemática com os professores da educação básica municipal pela busca de alternativas que tornem o ensino da matemática mais dinâmico e atrativo, levando-se em conta as peculiaridades da infraestrutura e dos recursos disponíveis nas escolas da rede municipal. Nesse sentido, os conhecimentos adquiridos no curso de Licenciatura em Matemática possibilitarão aos licenciandos o desenvolvimento de novas metodologias e materiais didáticos que possam suprir as reais necessidades vivenciadas nas escolas da rede pública.

A OSMEM proporcionará um ambiente propício para o exercício do binômio ensino/aprendizagem, de modo que professores e alunos serão estimulados a desenvolver o raciocínio lógico, o pensamento intuitivo, a compreender a importância da matemática em seu cotidiano e para as diversas áreas do saber. Este projeto é consequência das ações realizadas anteriormente pelo professor Péricles Crisiron

RC: 104950

Disponível em: https://www.nucleodoconhecimento.com.br/matematica/olimpiada-dematematica 
Pontes que foi pioneiro no município, o que serviu como base para a criação da OSMEM que se iniciou no município de Santana do Araguaia no segundo semestre do ano de 2018, e foi pioneira na região sul do Pará, proporcionando um avanço de qualidade para os alunos da rede municipal de ensino.

\section{OBJETIVOS DO PROJETO}

Através da parceria que será estabelecida entre os docentes da Unifesspa e da rede pública da educação básica para a realização da OSMEM pretende-se despertar nos estudantes do $6^{\circ}$ ao $9^{\circ}$ ano do ensino fundamental das escolas públicas de Santana do Araguaia o gosto pelo estudo da Matemática, bem como potencializar o desempenho dos mesmos na OBMEP, além de proporcionar aos discentes do curso de Licenciatura em Matemática do Instituto de Engenharia do Araguaia (IEA), UNIFESSPA - Campus Santana do Araguaia - experiências pedagógicas diversificadas do cotidiano escolar que possam contribuir com sua formação acadêmica e com a qualidade de ensino de matemática na educação básica.

Em linhas específicas esse projeto teve como intuitos de estimular e promover o estudo da Matemática entre os alunos das escolas públicas municipais de Santana do Araguaia; despertar nos alunos do Ensino Fundamental a curiosidade para pesquisar e a vontade de querer aprender e solucionar problemas matemáticos através de ações como a disponibilização de materiais didáticos e baterias de exercícios; contribuir para a integração das escolas municipais de Santana do Araguaia com a UNIFESSPA; promover a inclusão social através da difusão de conhecimentos da área da matemática; identificar jovens talentos que serão premiados pelos seus esforços segundo a Secretaria de Educação do Município de Santana do Araguaia; proporcionar momentos de capacitação aos professores do ensino Fundamental entre $6^{\circ}$ e $9^{\circ}$ ano, além de promover troca de experiências pedagógicas entre os profissionais envolvidos no projeto.

RC: 104950

Disponível em: https://www.nucleodoconhecimento.com.br/matematica/olimpiada-dematematica 


\section{EXECUÇÃO DO PROJETO}

Inicialmente, antes de qualquer passo, foi realizado uma visita em todas as escolas de ensino fundamental da cidade de Santana do Araguaia, na sua zona urbana, durante essas visitas foram realizadas reuniões com as equipes pedagógicas e professores que ensinam matemática do $6^{\circ}$ ao $9^{\circ}$ ano, para apresentação do projeto nessas unidades escolares, em seguida a equipe do projeto fez o convite pessoalmente em todas as salas de aula na qual o projeto abrangeria.

Em uma segunda etapa foram realizadas reuniões com toda a equipe do projeto composta inicialmente pelos Professores Me. Helves Belmiro da Silveira, Esp. Osmar Tharlles Borges de Oliveira, com os acadêmicos inscritos, inicialmente com Adriano Barroso Araújo e Laila Luiza Ribeiro, essas reuniões foram para tratar das estratégias que deveriam ser usadas durante a execução do projeto.

Na sequência foram traçadas as metas para a execução da OSMEM e colocadas em prática no projeto. É importante ressaltar que além do reforço matemático colocado nas aulas, as questões trabalhadas em sala de aula, foram extraídas das Olimpíadas Cearense de Matemática e da Olimpíadas Brasileira de Matemática das Escolas Públicas, haja visto que um dos objetivos era melhorar a participação dos alunos em olimpíadas de matemática nacionais.

As aulas do projeto aconteceram nas dependências da Universidade Federal do Sul e Sudeste do Pará, no campus de Santana do Araguaia, na sala 4, e inicialmente participaram 43 alunos, na sua maioria oriundos das escolas municipais Terezinha Abreu Vita e Irmão Pio Barroso, com mais de $90 \%$ dos participantes, deve-se destacar que essas escolas são as maiores do município e que as mesmas ficam a uma distância pequena da universidade. Logo a maior adesão desses alunos no projeto.

Os dias para a execução do projeto foram aos sábados pela manhã, as turmas foram divididas em dois horários por níveis, onde o primeiro era composto pelos $6^{\circ}$ e $7^{\circ}$ anos

RC: 104950

Disponível em: https://www.nucleodoconhecimento.com.br/matematica/olimpiada-dematematica 
e o segundo pelos $8^{\circ}$ e $9^{\circ}$ anos. O horário de execução foi das 8:00 às 9:30 para o primeiro nível e das 9:30 às 11:00 para o segundo nível. As aulas do projeto iniciaram em setembro de 2018 e durou até julho de 2021.

Vale ressaltar que antes da pandemia do COVID-19 as aulas funcionaram normalmente nas dependências da universidade e que a adesão de alunos das escolas do município era significativa, pois o projeto era bem-visto entre os professores do município que foram parceiros dessa iniciativa, porém com o cenário pandêmico a procura diminuiu, pois a maioria dos alunos não possuem acesso à internet, não possuem computadores e nem smartfones, o que inviabilizou o acesso de mais alunos a esse projeto.

Ainda em relação aos problemas provocados pela pandemia da COVID-19, a prefeitura municipal de Santana do Araguaia, não realizou essas olímpiadas, pois seguindo orientações da Organização Mundial da Saúde (OMS), a aglomeração de pessoas não é recomendada, já que favorece a proliferação da doença e por esse motivo a secretaria municipal de educação achou por bem não promover esse evento, o que foi acatado pela organização do projeto e pela equipe da universidade. Porém a SEMED (Secretaria Municipal de Educação) fez o compromisso de ao finalizar a pandemia retornarmos com o projeto e ao fim de cada ano será realizado evento.

\section{RESULTADOS ATINGIDOS}

Iniciaremos aqui alguns resultados que nos foi bastante favorável durante a aplicação do projeto de extensão OSMEM, e consideramos que o principal deles foi o engajamento dos alunos em entender que podem sim serem competitivos e aprenderem matemática de forma mais abstrata e formal, vale destacar o empenho do alunado em participar do projeto e levarem suas dúvidas e suas experiências pessoais para a sala de aula.

$\mathrm{RC}: 104950$

Disponível em: https://www.nucleodoconhecimento.com.br/matematica/olimpiada-dematematica 
Não poderíamos deixar de fora a parceria feita entre os profissionais da rede municipal de Santana do Araguaia e o projeto, em especial destaca-se os professores da rede, que sempre foram receptivos e parceiros do projeto, e que segundo eles ao se depararem com o interesse da universidade, buscaram novas metodologias para o ensino de matemática afim de tornarem o aprendizado da disciplina mais atraente, prazeroso e dinâmico em suas aulas. Durante a parceria os laços entre a equipe do projeto alguns profissionais da educação foram de suma importância, e destaca-se aqui o empenho e dedicação do professor Arlem Cunha, que sempre foi parceiro das iniciativas da universidade e colaborou de forma significativa com o desenvolvimento da OSMEM, não medindo esforços para a aprendizagem de seu alunado, destaca-se ainda a professora Ivanete Cirqueira e Souza Freitas que foi acadêmica da UNIFESSPA, e uma das maiores colaboradoras de projetos relacionados a matemática em Santana do Araguaia, pessoa fundamental para construir a ponte entre a universidade e as escolas do município e que infelizmente foi uma vítima fatal da COVID-19, mas que deixou o seu legado na educação e no empenho de ser uma profissional de excelência, fica o registro da equipe do projeto.

A aplicação do projeto resultou ainda na identificação de fragilidades no ensino de matemática e uma má formação dessa disciplina na base educacional, o que procurou-se sanar em todos os participantes, e que posteriormente foi discutido junto à comunidade educacional, gerando uma formação continuada para os professores de matemática daquele município, tal formação foi elaborada pelo corpo docente da UNIFESSPA e em específico, para os profissionais da matemática foi feita uma revisão das metodologias e dos livros didáticos usados, tal evento foi mediado pelo Professor Helves Belmiro da Silveira e teve participação de todos os professores de matemática da zona urbana do munícipio e alguns da zona rural.

Um resultado bastante significativo pra toda a equipe do projeto, foi o ingresso da maioria dos seus participantes na segunda fase da OBMEP, além de melhora nos seus rendimentos escolares, o que foi motivo de orgulho e agitação para toda a equipe

RC: 104950

Disponível em: https://www.nucleodoconhecimento.com.br/matematica/olimpiada-dematematica 
da OSMEM. O projeto ainda não conseguiu medalhas na OBMEP, mas, ao final da pandemia será retornado de forma presencial e com a participação de todos esperase conseguir medalhas e menções honrosas na olimpíada nacional, bem como a realização da olimpíada municipal.

Não poderia ficar de fora um outro resultado de suma importância, relacionado ao papel docente dos acadêmicos envolvidos no projeto, pois as experiências adquiridas durante a realização do projeto os fizeram capazes de sentir como funciona a prática da docência em sala, além da contribuição notória com o alunado do município.

\section{CONSIDERAÇÕES FINAIS}

Ao analisar todos os atingidos pelo projeto de extensão OSMEM, chega-se à conclusão da importância desse tipo de projeto para a comunidade de Santana do Araguaia e para os futuros docentes da área de matemática, essa via de mão dupla é responsável pelo desenvolvimento matemático dos alunos das escolas municipais e dos acadêmicos e por sua vez serão uma nova ferramenta nesse mercado, atuando com responsabilidade e contribuindo de forma significativa com o futuro educacional do município.

Ao retomarmos a questão norteadora desse projeto: por que estudar matemática em um contexto olímpico? Conclui-se que essa modalidade de ensino traz mais dinamismo e fortalece o ensino de conceitos da matemática pura em um âmbito escolar público, tornando possível que estudantes tenham o mesmo nível de competição dos grandes centros e desenvolvendo seu raciocínio lógico e matemático.

É importante ressaltar que os projetos relacionados a olimpíadas de matemática são ferramentas capazes de mudar de direção uma parcela da comunidade escolar onde os mesmos estão inseridos, novos talentos surgem sempre que estimulados e desafiados, e com essa afinidade é que o projeto de extensão OSMEM se instalou, afim de descobrir talentos espalhados no município de Santana do Araguaia - PA,

RC: 104950

Disponível em: https://www.nucleodoconhecimento.com.br/matematica/olimpiada-dematematica 
ressalta-se que por motivos da pandemia do COVID-19 o projeto não conseguiu atingir um público maior devido a falta de acesso da maioria dos alunos a recursos de informática tais como smartfones, notebooks e principalmente conectividade com a internet.

Registra-se nesse trabalho, o empenho dos professores da rede municipal, que foram verdadeiros parceiros no desenvolver do projeto, incentivando os alunos a participarem mesmo em tempos difíceis, proporcionando experiências diferentes e apoiando toda a equipe envolvida direta e indiretamente nesse trabalho.

\section{REFERÊNCIAS}

CASTRO, Luciana Maria Cerqueira. A universidade, a extensão universitária e a produção de conhecimentos emancipadores. Reunião anual da ANPED, v. 27, p. 1 16, 2004.

GADOTTI, Moacir. Extensão universitária: para quê. Instituto Paulo Freire, v. 15, 2017.

GOMES, Keyson Gondim. Olimpíada cearense de matemática (OCM): laboratório de oportunidades, experiências e de desenvolvimento da matemática no estado do Ceará. 2019.

MACIEL, Marcos Vinicius Milan; BASSO, Marcus Vinicius de Azevedo. Olimpíada Brasileira de Matemática das Escolas Públicas (OBMEP): as origens de um projeto de qualificação do ensino de matemática na educação básica. ljuí, RS, 2009

NUNES, Ana Lucia de Paula Ferreira; SILVA, Maria Batista da Cruz. A extensão universitária no ensino superior e a sociedade. Mal-Estar e Sociedade, v. 4, n. 7, p. 119-133, 2011.

RC: 104950

Disponível em: https://www.nucleodoconhecimento.com.br/matematica/olimpiada-dematematica 
RODRIGUES, Andréia Lilian Lima et al. Contribuições da extensão universitária na sociedade. Caderno de Graduação-Ciências Humanas e Sociais-UNIT-SERGIPE, v. 1, n. 2, p. 141-148, 2013.

SANTOS, João Henrique de Sousa; ROCHA, Bianca Ferreira; PASSAGLIO, Kátia Tomagnini. Extensão universitária e formação no ensino superior. Revista Brasileira de Extensão Universitária, v. 7, n. 1, p. 23-28, 2016.

Enviado: Outubro, 2021.

Aprovado: Janeiro, 2022. 